\title{
Cancer prevention and diet: opportunities in Europe
}

\author{
Elio Riboli* and Teresa Norat \\ Unit of Nutrition and Cancer, International Agency for Research on Cancer, 150 cours Albert-Thomas, \\ 69372 Lyon Cedex 08, France
}

\begin{abstract}
Over the past 20 years, a large number of epidemiological studies, particularly casecontrol and cohort studies, have been conducted to investigate the role of diet and the risk of developing different types of cancer. The most consistent finding so far is the association observed between consumption of vegetables and fruit and reduced risk of cancers of the digestive and respiratory tracts. More recently, evidence has accumulated indicating that high consumption of red meat (mainly beef, lamb and pork) and of preserved meat ('charcuterie') is specifically associated with a modest but significant increase in colorectal cancer risk. Finally, there is epidemiological evidence supporting an association between the risk of developing gastric cancer and the intake of salt and salt-preserved foods.

Cancer incidence and dietary habits vary substantially across Europe, and the expected benefit of dietary changes may be somewhat different in different populations. Despite some uncertainty, it is generally agreed that an increase in the consumption of vegetables and fruits and a decrease in the intake of red meat, processed meat, alcoholic beverages, salt and salt-preserved foods should contribute to a reduction in the incidence of cancers of the digestive and respiratory tract.
\end{abstract}

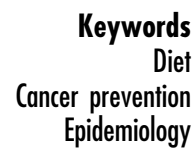

Descriptive epidemiology of cancer has shown that the incidence of most cancers varies widely in different populations around the world and within Europe. Cancer of the breast, colorectum, prostate, endometrium, ovary and lung are generally much more frequent in the economically more developed countries of Europe, North America and Australia and much less frequent in developing countries of Asia and Africa. On the other hand, cancers of the stomach, liver, oesophagus and cervix uteri are more frequent in developing countries of central and south America, Africa and Asia ${ }^{1}$.

In recent years, changes in lifestyle and diet which occurred in Japan were followed by a rapid increase in the incidence of colorectal cancer (which is now at the level of Western Europe) and of breast cancer (to a lesser extent), suggesting the possibility of an association. It is worth noting that the highest incidence of colorectal cancer so far reported in the world is among Hawaiians of Japanese origin, who have adopted a western style diet.

Even within Europe both the incidence of and mortality from most of these cancers varies two- or three-fold. Cancer incidence is generally lower in southern Mediterranean countries than in central and northern Europe, with the notable exception of gastric cancer which is more frequent on the Iberian peninsula and northern and central Italy than in the rest of Europe (see Figs 1a and $1 b)^{2}$.
Many of these observations were made more than 30 years ago with the publication of the first reliable data on cancer incidence from population cancer registries ${ }^{3,4}$, and they constitute one of the basic arguments for the hypothesis that lifestyle and environment play an important role in cancer etiology.

Over the past 20 years, a large number of epidemiological studies, particularly case-control studies and, more recently, large cohort studies, have been conducted to investigate the role of habitual diet and the risk of developing different types of cancer. Both epidemiological and experimental data on diet and cancer have been reviewed recently by three major working groups:

- One in the UK, the Committee on Medical Aspects of Food and Nutrition Policy (COMA) Working Group on Diet and Cancer $^{5}$;

- One in France, the Commission 'Prévention des Cancer par l'Alimentation' of the 'Centre National d'Etudes et de Recommandations sur la Nutrition et l'Alimentation' (CNERNA-CNRS-INRA) ${ }^{6}$;

- One at the international level, the World Cancer Research Fund/American Institute for Cancer Research (WCRF/AICR) ${ }^{7}$.

The three working groups reached very similar conclusions which were published in three extensive 


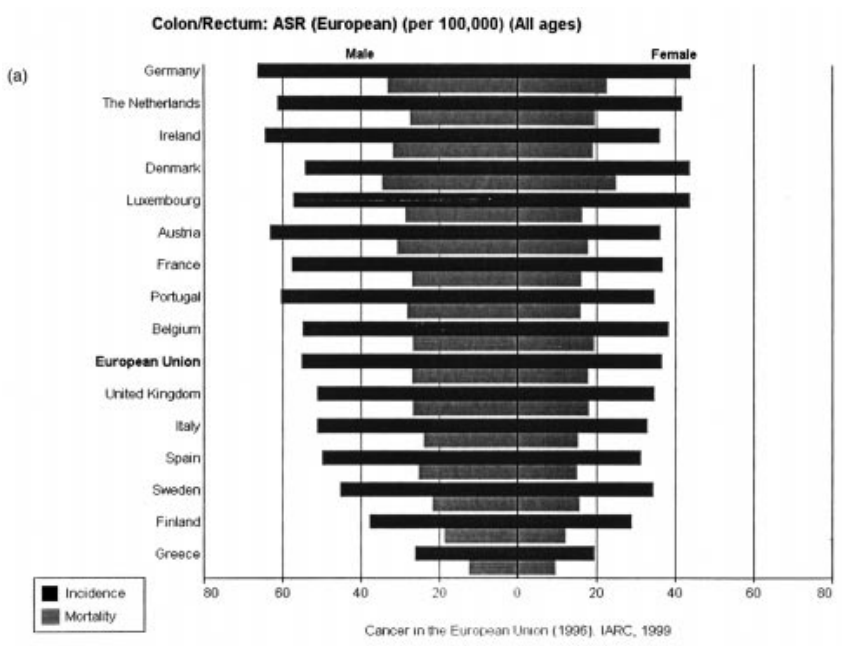

Female breast: ASR (European) (per 100,000) (All ages)

(b)

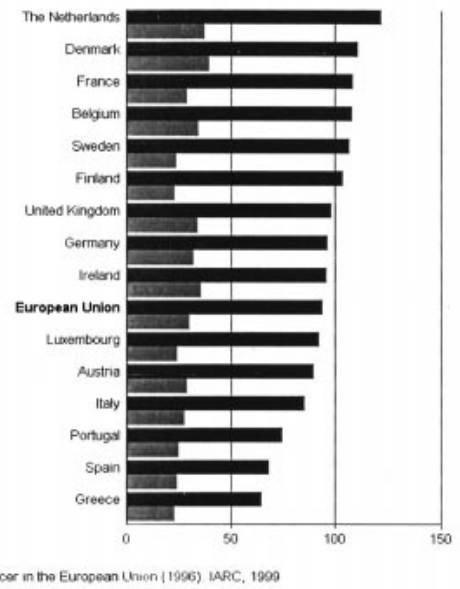

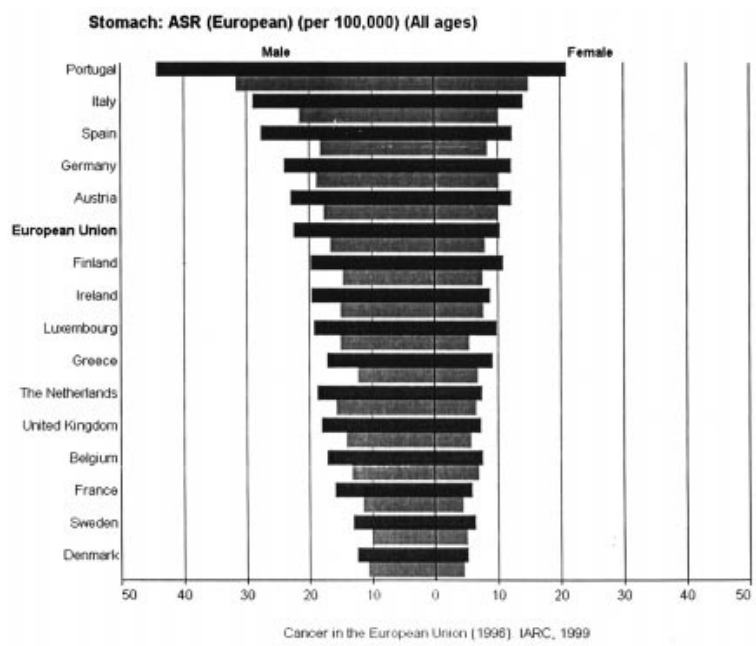

Prostate: ASR (European) (per 100,000) (All ages)

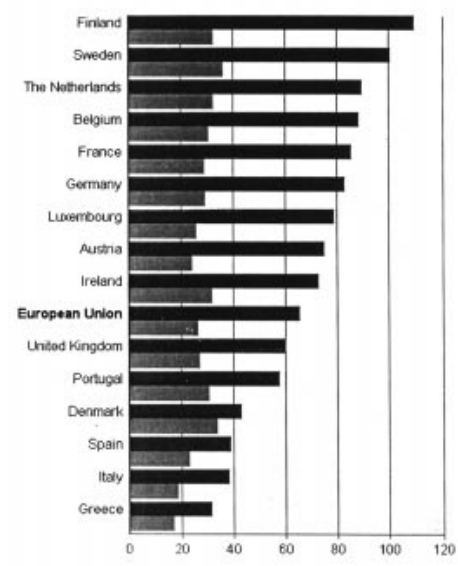

Concer in the Europeen Uhion (1996) IARC, 1990

Fig. 1 Incidence of cancer among men and women in the 15 EC countries: (a) Colorectum and stomach, (b) breast and prostate

reports $^{5-7}$. As a global review of diet and cancer would require over 1000 references of epidemiological studies, we refer to these three monographs as pertinent sources of information, except for major recently published papers. In this brief document we will voluntarily restrict ourselves to the major hypotheses and findings regarding nutritional factors, including anthropometry and cancer.

\section{Foods, dietary patterns and cancer risk}

The most consistent finding in diet and cancer research is the association observed between consumption of vegetables and fruit and reduced risk of several cancers. The three monographs cited above all indicate that vegetables and fruit are associated with reduced risk of cancers of the pharynx, larynx, lung, oesophagus, stomach and cervix uteri, while only vegetables but not fruit seem to protect against cancer of the colon and rectum. The foods for which a positive association with cancer risk has been found consistently are red and processed meat for colorectal cancer and Chinese-style salted fish for nasopharyngeal cancer (in south-east Asia only) (Table 1).

The protective effect of vegetable and fruit consumption was first suggested by case-control studies conducted in the 1970s and repeatedly confirmed over the last 20 years. The relative risks found in many epidemiological studies suggest that comparatively high intake of vegetables and fruit may reduce by up to $50 \%$ the risk of developing cancers of the digestive and respiratory tract, irrespective of other possible risk factors such as alcohol, tobacco, obesity and physical activity.

More precise quantitative estimates are being elaborated within a project conducted by us at IARC with the support of the WCRF. Preliminary results on colorectal cancer indicate that an average consumption of more than $500 \mathrm{~g}$ of vegetables per day may lead to a reduction in risk of the order of $60 \%$. Notable exceptions to the global epidemiological evidence on vegetables are the recent results from the USA of two cohort studies on colorectal cancer and consumption of vegetables and $\mathrm{fruit}^{8}$, and of two clinical trials in the USA which found that 
Table 1 Overview of the strength of the association found in epidemiological studies between some foods and the risk of developing certain types of cancer. Evidence of increased risk: $\uparrow \uparrow \uparrow=$ convincing, $\uparrow \uparrow=$ probable, $\uparrow=$ possible. Evidence of reduced risk: $\downarrow \downarrow \downarrow=$ convincing, $\downarrow \downarrow=$ probable, $\downarrow=$ possible. No association with cancer risk $=-$

\begin{tabular}{lllllll}
\hline & Vegetables & Fruit & (Red) Meat & Processed Meat & Salt & Alcohol \\
\hline Mouth/Pharynx/Larynx & $\downarrow \downarrow \downarrow$ & $\downarrow \downarrow \downarrow$ & - & - & - & $-1 \uparrow$ \\
Osophagus & $\downarrow \downarrow \downarrow$ & $\downarrow \downarrow \downarrow$ & - & - & - & $-1 \uparrow$ \\
Stomach & $\downarrow \downarrow \downarrow$ & $\downarrow \downarrow \downarrow$ & - & - & - & - \\
Colorectum & $\downarrow \downarrow \downarrow$ & $\downarrow$ & $\uparrow \uparrow$ & - & - & - \\
Breast & $\downarrow$ & $\downarrow$ & - & - \\
Lung & $\downarrow \downarrow \downarrow$ & $\downarrow$ & - & - & - \\
Prostate & $\downarrow$ & - & $\uparrow$ & & - \\
\hline
\end{tabular}

supplementation with high-fibre cereals and a switch to a low-fat, high-fibre diet did not prevent the recurrence of colorectal polyps (which are precursor lesions of colorectal cancer $)^{9,10}$. While the interpretation of these results, and particularly of the clinical trials, in terms of the longterm effect of a high-vegetable diet on colorectal cancer risk is quite complex, the overall picture remains supportive of a protective effect of vegetable intake on colorectal cancer.

From current studies it is not possible to say whether this protection is due to vegetables and fruit in general or more specifically related to the intake of some types of plant products. The authors' opinion is that the consistency of the results provided by studies conducted in different continents and in populations consuming different types of fruits and vegetables suggest that the protective effect is likely to be due to a variety of chemicals and physical characteristics widely and commonly present in most vegetables and fruits worldwide.

While vegetable and fruit intake has been found to be protective for a variety of cancers, meat consumption has been found to be specifically associated with an increased risk of developing colorectal cancer. The epidemiological studies examining the meat-colorectal cancer association were reviewed recently ${ }^{11}$. Total consumption of all types of meat and meat products including beef, pork, lamb, chicken and processed meats does not increase colorectal cancer risk when consumption of all types of meat and meat products (including beef, pork, lamb, chicken and processed meats) is considered as a single variable. Only 4 out of 24 case-control studies and one out of 6 cohort studies found a significant association. The results, however, are more supportive of an association for processed meats and red meat.

The processed meat category included very different food items ranging from ham, raw ham, sausages, various types of dried and salted meats as well as French-style delicatessen-like 'paté'. Eleven out of the 23 case-control studies and 2 out of 6 prospective cohort studies found a significantly increased risk for processed meat. Because of the heterogeneity of the foods included in the 'processed meat' category, however, it is not possible to identify any particular foods which may be more specifically associated with colorectal cancer risk.

For red meat, 5 out of 14 case-control studies and 2 out of 10 prospective studies found a significantly increased risk. The same authors conducted a statistical metaanalysis of the results of all the studies published so far on meat and colorectal cancer, and estimated the relative risk corresponding to a daily consumption of 40 and $80 \mathrm{~g}$ of different meat products. The results indicate that, for a similar hypothetical level of consumption, the increase in risk is stronger for processed meat than for red meat. On the other hand, the pooled relative risk for consumption of total fresh meat, not including processed meat, was about 1 , indicating that overall there is no evidence of an increased risk $^{12}$.

In the light of these results it is important for future prevention strategies to consider that studies on dietary habits show that between the north and the south of Europe there are up to five-fold variations in mean vegetable intake ranging from 370-500 g/day in Greece (women and men, respectively) to about $100 \mathrm{~g} /$ day in Iceland and Norway (Fig. 2a). Variations in average total meat consumption across European populations are not as large as for vegetables. However, the type of meat varies considerably in different countries, with quite different proportions of red meats (beef, veal, lamb and pork) and other processed meats, which is very interesting in view of the results summarized above on the association found between colorectal cancer risk and consumption of different types of meat ('red' meat, preserved meat) but not of others (chicken) (Fig. 2c). Large variations also exist in fruit consumption, although in this case there is no clear south-north trend as is the case for vegetables (Fig. 2b).

\section{Protein, carbohydrates and fat}

Epidemiological studies on diet and cancer present well known specific methodological difficulties, the most important being the complexity of measuring usual long-term diet at the individual level. The investigation of nutrient intake presents the additional difficulty of how to estimate the nutrient content of foods which, in most 
(a)

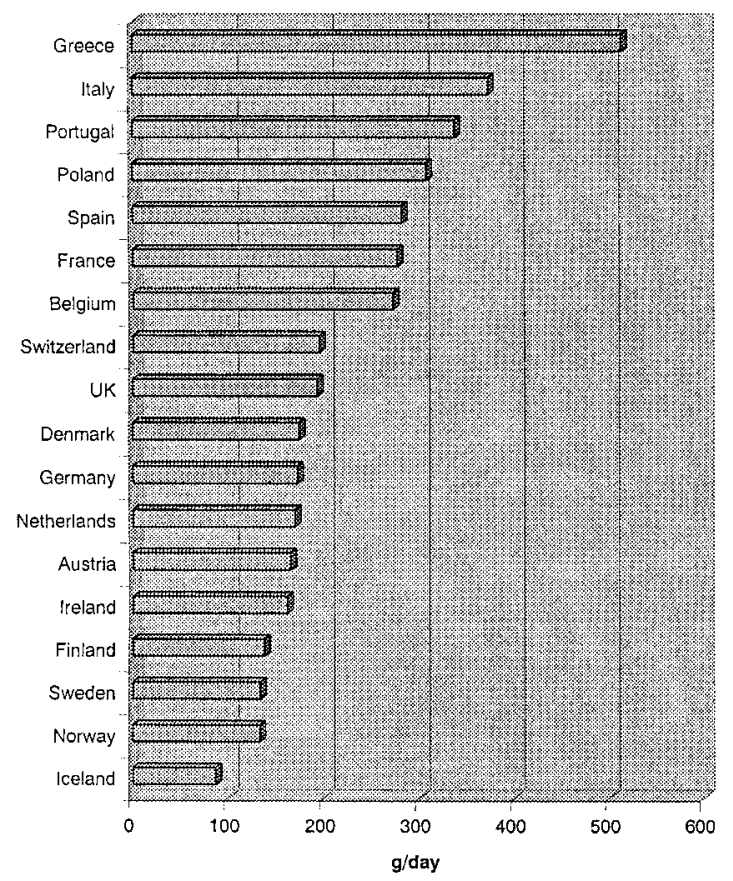

(b)

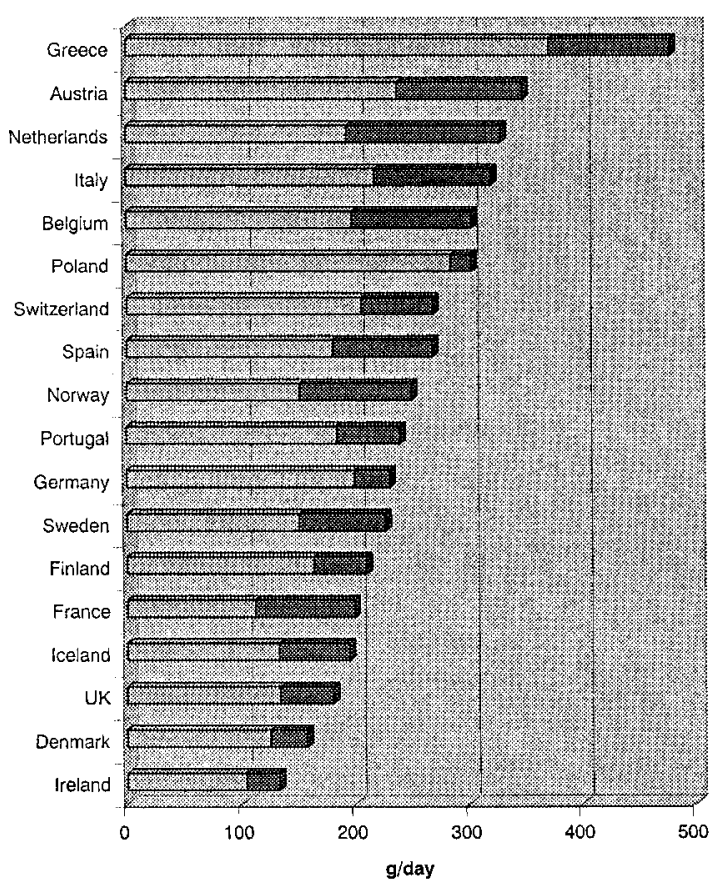

Women

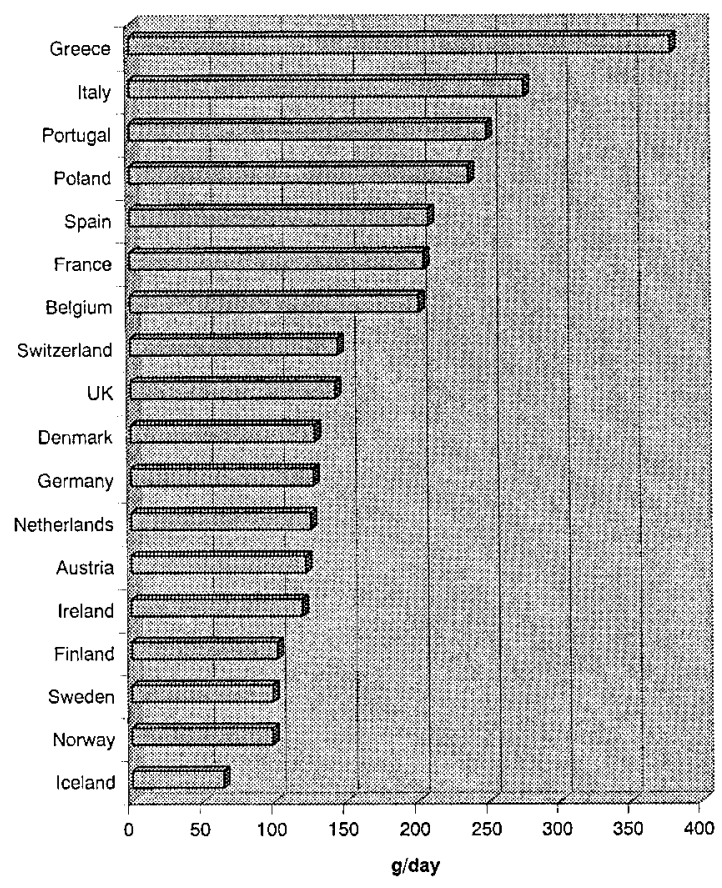

Women

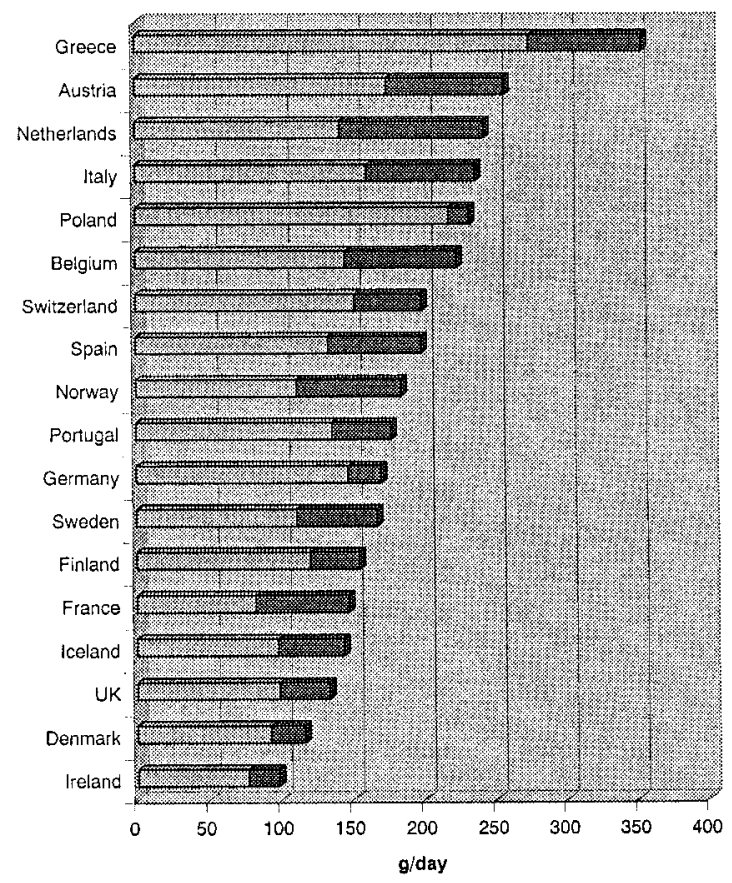

\section{All Fruits \\ Citrus Fruits}

Fig. 2 Per capita consumption of vegetables (a), fruit (b) and meat (c) in 18 European countries 
(c)

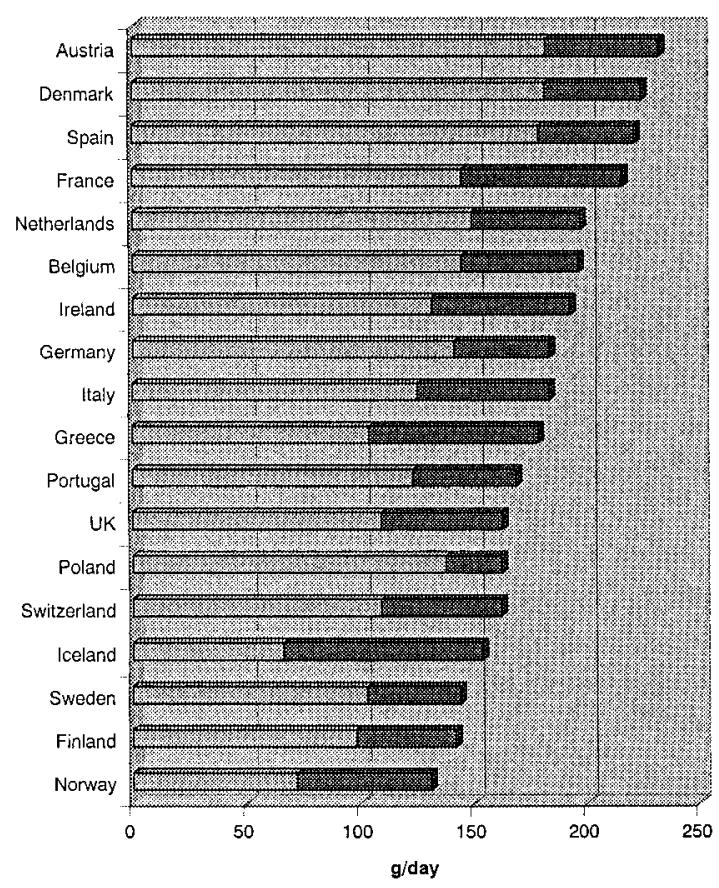

Men

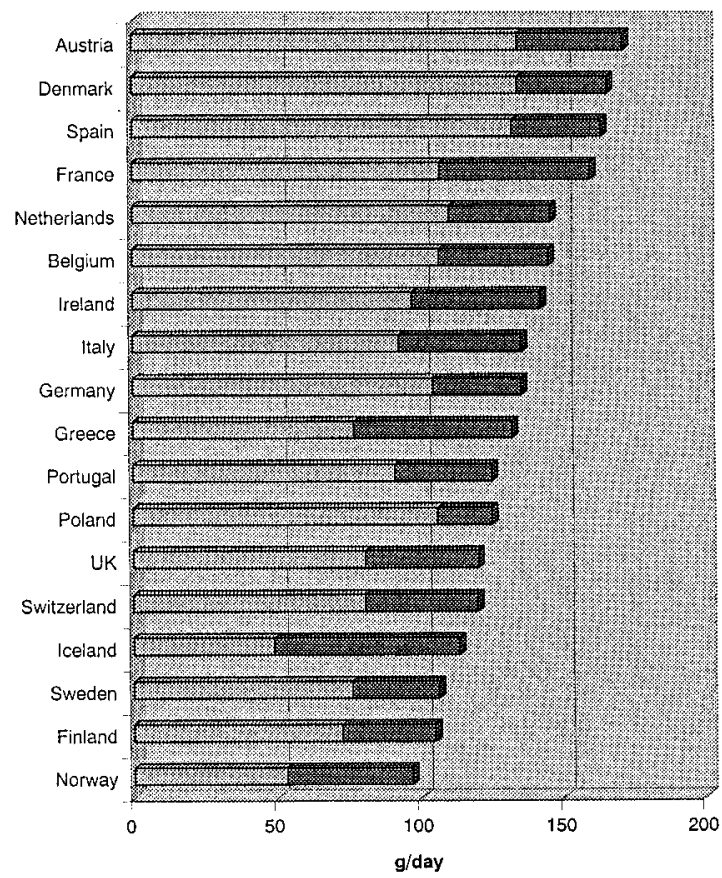

\section{All Meats \\ 2.. Red Meat}

\section{Fig. 2 Continued}

food consumption questionnaires, correspond to more or less heterogeneous categories of foods. For these food categories, only averaged and approximate food composition values can be used. These methodological considerations may, to some extent, explain why the results of epidemiological studies on nutrients have generally given less consistent results than those on foods. This is particularly true for macronutrients and energy.

The results of epidemiological studies on macronutrients have so far been much less consistent that those on foods. No clear risk patterns have emerged for consumption of protein. Some studies on oesophageal cancer in populations with high alcohol intake found a protective effect for animal protein (and meat) while some studies on colorectal cancer found an increased risk for animal protein (and meat).

Results on carbohydrates are difficult to interpret because of inconsistencies in the way different food composition tables subdivide total carbohydrates into sub-fractions that have very different physiological and metabolic effects and which may affect carcinogenesis in opposite ways. The only pattern that seems to emerge so far is that consumption of simple sugars (mono- and di-saccharides) may be associated with increased colorectal cancer risk, while consumption of complex polysaccharides, non-starch polysaccharides and/or fibre (partially overlapping categories based on different chemical and physiological definitions) are associated with lower cancer risk. Other less consistent findings suggest that a diet excessively rich in starchy foods (mainly beans, flour products or simple sugars) but also poor in fruit and vegetables, may be associated with increased gastric cancer risk.

The hypothesis that high fat intake is a major cancer risk factor of the western-style diet has been at the centre of most epidemiological and laboratory experimental studies. The results are, however, far from clear and definitive. A positive association with risk of cancers of the breast and colorectum was suggested by studies which found a positive and significant correlation between per capita intake of fat, especially fat of animal origin, and incidence of breast cancer in different populations around the world ${ }^{13}$. Case-control and cohort studies, however, generally found either weak associations between fat intake and cancer risk $^{14}$ or no association, particularly after statistical adjustment for total energy intake $e^{15,16}$.

A recent re-analysis of six large prospective studies 
conducted in Europe and North America (for a total of 322000 women, among whom 4827 breast cancer cases occurred during follow-up) investigated the relation between breast cancer incidence and characteristics of sexual maturation and reproductive life and their possible interaction with fat intake in adult life. This study strongly confirmed that breast cancer incidence was higher in women who had early menarche, late menopause, low parity and late age at first birth. In addition, breast cancer incidence was found to be higher in women who had suffered from benign breast disease and women whose mother or sister had breast cancer. Fat intake was not associated with breast cancer incidence in the total cohort, nor in any of the subgroups defined by these confirmed risk factors. Despite the accumulation of epidemiological studies which did not find any relationship between fat intake and breast cancer, it is still possible that a weak relationship exists, but it is obscured by the effect of random dietary measurement error ${ }^{17}$.

The effect of the balance between different types of fats, mainly of $n-3$ and $n-6$ polyunsaturated, monounsaturated (n-9) or saturated fatty acids, has been investigated in many laboratory studies in vitro and in vivo but in very few epidemiological studies. Animal experiments have generally indicated that high-fat diets rich in $n-6$ polyunsaturated fatty acids (PUFA) (mainly linoleic acid) generally stimulated mammary tumour development and metastasis, whereas diets rich in n-3 polyunsaturated fatty acids (mainly alpha-linolenic, eicosapentaenoic and Docosahexaenoic acids) appeared to inhibit tumour growth and metastasis ${ }^{18}$. Epidemiological studies in which fat intake has been assessed in individuals by questionnaire methods have generally provided weak or no support for the hypothesis that dietary intake of $n-3$ PUFA might protect against breast or colorectal cancer. Although some case control-studies ${ }^{19-22}$ showed inverse associations between breast cancer risk and consumption of fish rich in long-chain n-3 PUFA, these findings were not confirmed by several prospective cohort studies ${ }^{23,24}$. Pooled analyses of multiple case-control ${ }^{14}$ or cohort studies $^{16}$ showed no association between intake of PUFA and risk of breast cancer. In none of these studies, however, was any distinction made between n-6 and n-3 PUFA.

These limitations were overcome by two recent prospective cohort studies conducted in Sweden and Italy in which fatty acid composition was measured by laboratory analyses of fatty acids in blood samples collected at baseline years before breast cancer was diagnosed $^{25}$ and Pala et al., personal communication. The main findings of these studies were an absence of association between breast cancer risk and blood levels of $n-3$ PUFA. In conclusion, there is no clear evidence that, in humans, n-3 PUFA reduces breast cancer risk.

\section{Alcohol}

There is sufficient evidence that alcoholic beverages are carcinogenic to humans ${ }^{26}$. The debate is still open, however, on the net effect of moderate alcohol consumption on all-cause mortality. Some studies which found lower total mortality among moderate drinkers have been given much publicity by the media. It has been claimed that red wine may be more protective against cardiovascular disease (and even against cancer) than other alcoholic beverages such as beer. Other studies, however, suggested that the benefit may be restricted to men and to populations with high cardiovascular risk.

\section{Salt and salt-preserved foods}

The hypothesis that high intake of salt and salt-preserved foods was among the first investigated 20-30 years ago in relation to the etiology of gastric cancer. The Intersalt Study covering 24 countries showed that gastric cancer incidence tends to be higher in populations where salt intake is high (correlation: 0.7$)^{27}$ In recent decades more than a dozen case-control studies have provided results consistent with this hypothesis. Salt in itself does not seem to be a carcinogen in rodents, but it causes gastric metaplasia, a precursor lesion in the gastric cancer pathway $^{28}$. In addition, salt-presented foods may contain a large variety of nitroso compounds, either added during food preparation (nitrites) or formed endogenously.

\section{Intake of vitamins and minerals}

The starting point for research on some vitamins and cancer was the observation that high consumption of vegetables and fruits is associated with reduced cancer risk. Over the past two decades, epidemiological studies on vitamins and cancer in humans has mainly focused on carotenoids and vitamin A (retinol), vitamin E, vitamin C and some of the group of $\mathrm{B}$ vitamins (folic acid, $\mathrm{B}_{6}$ ). The biological basis of the interest in these vitamins is their involvement in either of two metabolic mechanisms commonly called antioxidant effect (carotenoids, vitamins $\mathrm{C}$ and $\mathrm{E}$ ) and methyl donation (folic acid, $\mathrm{B}_{6}$ ).

\section{Carotenoids}

Case-control studies based on dietary questionnaires and several small prospective cohort studies based on blood measurements have shown quite consistently that subjects with lower levels of beta-carotene and other carotenoids had increased lung cancer risk. Less consistent and weaker protective effects of carotenoids have also been reported for cancers of the oesophagus, stomach, colorectum, breast and cervix. 


\section{Vitamin C}

Low dietary intake of vitamin $\mathrm{C}$ has been found to be associated with increased risk of cancers of the stomach, mouth, pharynx, oesophagus and, less consistently, with cancers of the lung, pancreas and cervix.

\section{Vitamin E}

Although results on vitamin $\mathrm{E}$ and cancer are less strong and consistent than those on carotenoids and vitamin $\mathrm{C}$, several studies have suggested that low vitamin E intake is related to increased risk of cancers of the lung, cervix and colorectum.

\section{Folates and vitamin $B$}

There is rising interest in the possible cancer preventive effect of folic acid for which some prospective studies have shown that high dietary intakes and higher blood levels may be associated with reduced risk of cancers and adenomatous polyps of the colorectum. Folates and vitamin $\mathrm{B} 6$ are involved in the synthesis of methionine and choline as methyl donors. Folate deficiency leads to an accumulation of homocysteine. High homocysteine levels have recently been found to be strongly predictive of death from myocardial infarction, total mortality and (possibly) cancer mortality ${ }^{29,30}$. Two recent randomized clinical trials found a modest protection against recurrence of colorectal polyps in subjects taking supplements of non-absorbable calcium salt ${ }^{31,32}$.

\section{Minerals}

Epidemiological studies conducted in populations with high incidence of oesophageal cancer in China found that zinc deficiency was common among these populations. Some experimental studies also suggest that selenium deficiency may increase cancer risk. Several epidemiological studies have examined the association between cancer risk and deficiencies of one of these minerals, with very variable results.

\section{Clinical trials on chemoprevention based on supplementation with vitamins and minerals}

Following the results of epidemiological studies on antioxidant vitamins, several clinical trials were undertaken with beta-carotene and vitamins $\mathrm{E}$ and $\mathrm{C}$ in relation to cancer of the lung, oesophagus and stomach and several precancerous lesions (oral leukoplakia and colorectal adenomas). These studies produced varying results. None of the four large trials on beta-carotene and lung cancer found a protective effect.
On the contrary, two of them (ATBC, in Finland and CARET, in the USA $)^{33,34}$ observed increases in lung cancer incidence of $18 \%$ and $28 \%$, respectively, in the betacarotene group (beta-carotene plus vitamin A in CARET). In the $\mathrm{ATBC}$ study the group receiving a vitamin $\mathrm{E}$ supplement had a 34\% reduction in prostate cancer incidence, but deaths from cerebro-vascular accidents doubled, and there was no decrease in total mortality.

Several combinations of vitamins and minerals were tested in a large Chinese trial, and one of these (betacarotene+vitamin E+selenium) led to a $13 \%$ reduction in total cancer mortality, a significant $21 \%$ reduction in stomach cancer mortality, but no significant reduction in oesophageal cancer, which was the primary target of the study ${ }^{35}$. Recently a clinical trial, originally designed to investigate the prevention of the recurrence of nonmelanoma skin cancer found, in a secondary endpoint analysis, that the incidence of prostate cancer was 63\% lower among those treated with selenium compared to those receiving a placebo ${ }^{36}$.

So far the studies on precancerous lesions have produced quite differing results; for colorectal polyps, the largest trials found no protection from supplementation with vitamin $\mathrm{C}$ and beta-carotene, whereas for oral leukoplakia several studies showed that beta-carotene had rapid and significant effects on total or partial reduction in lesions.

An issue which is of primary concern for investigations on diet and cancer is to what extent these rather disappointing results (with the possible exception of those on selenium) on cancer chemoprevention and antioxidants negate the results obtained in observational epidemiological studies on the same compounds and on fruit and vegetables. There are at least two important differences between these clinical trials and studies on diet. The first is the dose; the clinical trials used doses of beta-carotene ( 15 to $25 \mathrm{mg}$ per day) which led to blood concentrations 10 to 20 times higher than those achievable through high dietary intake of fruit and vegetables. The second is that clinical trials generally tested one or two compounds at a time, at high doses, while fruit and vegetables represent a complex mixture of hundreds of natural compounds.

Regarding future research in this area, the quite different results of clinical trials suggest that observational studies combining dietary data and biological markers of diet should be exploited more thoroughly to identify combinations of nutrients that might be associated with cancer prevention, and which may be candidates for experimental studies on laboratory animals and, eventually, for chemoprevention trials in humans ${ }^{37,38}$.

\section{Overweight and obesity}

Epidemiological studies have shown with varying degrees of consistency that excess body mass (usually estimated as 
weight/height squared, or body mass index) is associated with increased risk of cancer of the endometrium, breast and colon. It has been suggested that there may be an association between anthropometric characteristics and risk of cancer at other sites, but the data are more inconsistent. The strongest and most consistent association between body mass has so far been seen for endometrial cancer, the risk of which is increased two- to six-fold in obese compared to lean women, both before and after menopause. A possible biological explanation for this association is that adipose tissue is rich in aromatase which converts androstenedione to oestrone, thus increasing oestrogenic stimulation of the endometrial mucosa, although other mechanisms may be possible ${ }^{39}$. Several studies have investigated markers of fat distribution such as weight-to-hip ratio (WHR) or subscapular-to-tightskinfold ratio (STR) in relation to endometrial cancer risk with inconsistent results. Some studies found increased risk for markers of abdominal or android obesity (high WHR or STR) after adjustment for BMI (body mass index), while others did not. The relationship between BMI and breast cancer is even more complex. The majority of case-control and prospective studies found that high BMI increased breast cancer risk in post-menopausal women, while it may slightly reduce risk in premenopausal women. A possible explanation for this apparent paradox is that overweight before menopause could be related to anovulatory cycles, and fewer ovulatory cycles (as determined by pregnancy and lactation) are generally associated with lower breast cancer risk. After menopause, obesity may act as for endometrial cancer by enhancing the peripheral (as opposed to gonadal and critical) production of oestrogens.

An interesting finding of the US Nurses Cohort is the important role of weight gain from the age of 20 to middle age in determining the increase in risk of postmenopausal breast cancer ${ }^{40}$.

\section{Conclusions}

There is growing evidence that metabolic factors related to diet, nutritional status, anthropometry and physical activity have an influence on the development and clinical appearance of various forms of cancer. Epidemiological studies have so far indicated that different dietary patterns may be specifically related to higher risk of particular types of cancer. Western diet and lifestyle are generally associated with high incidence of cancers of the colorectum, breast, prostate and endometrium, but with low incidence of cancers of the stomach, oesophagus, liver and cervix uteri. The most consistent results of epidemiological studies so far are that diets rich in fruit and vegetables can reduce the risk of cancer of the digestive and respiratory tract while high consumption of red meat and meat products may increase colorectal cancer risk, and high consumption of salt can increase gastric cancer risk.

On the other hand, data have accumulated suggesting that some metabolic factors related to nutritional status, such as obesity and physical activity, may also play a role by increasing the risk of certain cancers, as seems to be the case for cancer of the breast and endometrium. Several prospective studies have lent strong support for the hypothesis formulated decades ago regarding the prominent role of endogenous hormone levels in determining risk of cancer of the breast. Variations in the pattern of oestrogens, androgens, IGF and their binding proteins are probably determined by both environmental and lifestyle factors, as well as by inherited genetic characteristics, as suggested by recent studies on polymorphisms of genes encoding for enzymes regulating steroid hormone metabolism and hormone receptors.

All these and other results reviewed in this document indicate that the relationship between diet and cancer is much more complex than was previously thought. Research based on a combination of laboratory investigations on human subjects and sound epidemiological projects of a prospective nature is likely to shed new light on the link between nutritionally related factors and cancer. In the meantime, public health recommendations should focus on the benefits which can be expected from a diet rich in vegetables and fruit, the avoidance of overweight and a physically active lifestyle.

\section{Acknowledgements}

This work was partialy supported by a grant from the World Cancer Research Fund.

\section{References}

1 Parkin DM, Whelan SL, Ferlay J, Raymond L, Young J. Cancer Incidence in Five Continents. Vol. VII. IARC Scientific Publication No 143. Lyon: International Agency for Research on Cancer, 1997.

2 Ferlay J, Black RJ, Pisani P, Valdivieso MT, Parkin DM. EUROCAN90: Cancer in the European Union (Electronic Database with Graphic Display). Lyon: International Agency for Research on Cancer, 1996.

3 Doll R, Payne P, Waterhouse J, eds. Cancer Incidence in Five Continents: A Technical Report. Berlin: Springer-Verlag (for UICC), 1966.

4 Doll R, Muir C, Waterhouse J, eds. Cancer Incidence in Five Continents, Volume II. Berlin: Springer-Verlag (for UICC), 1970.

5 COMA Working Group on Diet and Cancer. Nutritional Aspects of the Development of Cancer. UK Department of Health Report on Health and Social Subjects No. 48. Norwich: HMSO.

6 Riboli E, Decloitre F, Collet-Ribbing C, eds. Alimentation et Cancer: Evaluation des Données Scientifiques. Paris: Lavoisier, 1996.

7 WCRF/AICR. Food, Nutrition and the Prevention of Cancer: 
a Global Perspective. Washington DC: World Cancer Research Fund/American Institute of Cancer Research, 1997.

8 Michels DK, Giovannucci E, Joshipura KJ, Rosner BA, Stampfer MJ, Fuchs CS, Colditz GA, Speizer FE, Willett WC. Prospective study of fruit and vegetable consumption and incidence of colon and rectal cancers. J. Natl. Cancer Inst. 2000; 92: 1740-52.

9 Schatzkin A, Lanza E, Corle D, Lance P, Iber F, Caan B, Shike M, Weissfeld J, Burt R, Cooper MR, Kikendall JW, Cahill J. The Polyp Prevention Trial Study Group (2000). Lack of effect of a low-fat, high-fiber diet on the recurrence of colorectal adenomas. N. Engl. J. Med. 1997; 342: 1149-55.

10 Albert DS, MartInez ME, Roe DJ, Guillén-RodrÍguez JM, Marshall JR, van Leeuwen JB, Reid ME, Ritenbaugh C, Vargas PA, Bhattacharyya AB, Earnest DL, Sampliner RE. The Phoenix Colon Cancer Prevention Physicians' Network. Lack of effect of a high-fiber cereal supplement on the recurrence of colorectal adenomas. N. Engl. J. Med. 2000; 342: 1156-62.

11 Norat T, Riboli E. Meat consumption and colorectal cancer: A review of epidemiological evidence. Nutr. Rev. 2001; 59: $37-47$.

12 Norat T, Lukanova A, Ferrari P, Riboli E. How much colorectal cancer could be prevented by lowering meat consumption? A meta-analysis of epidemiological studies (Poster presented at the 10 Annual Research Conference of the AICR, Washington DC, 31.8-1.9.00).

13 Armstrong B, Doll R. Environmental factors and cancer incidence and mortality in different countries, with special reference to dietary practices. Int. J. Cancer 1997; 15: 617-31.

14 Howe GR, Hirohata T, Hislop G, Iscovich JM, Yuan JM, Katsouyanni K, Lubin F, Marubini E, Modan B, Rohan T, Toniolo P, Yu S. Dietary factors and risk of breast cancer: Combined analysis of 12 case-control studies. J. Natl. Cancer Inst. 1990; 82: 561-9.

15 Howe GR, Aronson KJ, Benito E, Castelleto R, Cornée J, Duffy S, Gallagher RP, Iscovich JM, Deng-Ao J, Kaaks R, Kune GA, Kune S, Lee HP, Lee M, Miller AB, Peters RK, Potter JD, Riboli E, Slattery ML, Trichopoulos D, Tuyns A, Tzonou A, Watson LF, Whittemore AS, Wu-Williams AH, Shu $\mathrm{Z}$. The relationship between dietary fat intake and risk of colorectal cancer: Evidence from the combined analysis of 13 case-control studies. Cancer Causes Control 1997; 8: $215-28$.

16 Hunter DJ, Spiegelman D, Adami HO, Beeson L, van den Brandt PA, Folsom AR, Fraser GE, Goldbohm RA, Graham S, Howe GR, et al. Cohort studies of fat intake and the risk of breast cancer - a pooled analysis. N. Engl.J. Med. 1996; 334: 356-61.

17 Prentice RL, Sheppard L. Dietary fat and cancer: consistency of the epidemiologic data, and disease prevention that may follow from a practical reduction in fat consumption. Cancer Causes Control 1990; 1: 81-97.

18 Fay MP, Freedman LS, Clifford CK, Midthune DN. Effect of different types and amounts of fat on the development of mammary tumors in rodents: a review. Cancer Res. 1997; 57: 3979-88

19 Ingram DM, Nottage E, Roberts T. The role of diet in the development of breast cancer: a case-control study of patients with breast cancer, benign epithelial hyperplasia and fibrocystic disease of the breast. Br. J. Cancer 1991; 64: 187-91.

20 Landa MC, Frago N, Tres A. Diet and the risk of breast cancer in Spain. Eur. J. Cancer Prev. 1994; 3: 313-20.

21 Franceschi S, Favero A, La Vecchia C, Negri E, Dal Maso L, Salvini S, De Carli A, Giacosa A. Influence of food groups and food diversity on breast cancer risk in Italy. Int. J. Cancer 1995; 63: 785-9.

22 Braga C, La Vecchia C, Negri E, Franceschi S, Parpinel M.
Intake of selected foods and nutrients and breast cancer risk: an age- and menopause-specific analysis. Nutr. Cancer 1997; 28: 258-63.

23 Vatten LJ, Solvoll K, Løken EB. Frequency of meat and fish intake and risk of breast cancer in a prospective study of 14500 Norwegian women. Int. J. Cancer 1990; 46: $12-5$.

24 Toniolo P, Riboli E, Shore RE, Pasternack BS. Consumption of meat, animal products, protein, and fat and risk of breast cancer: A prospective cohort study in New York. Epidemiology 1994; 5: 391-7.

25 Chajès V, Hultén K, van Kappel AL, Winkvist A, Kaaks R, Hallmans G, Lenner P, Riboli E. Fatty acid composition in serum phosopholipids and risk of breast cancer: an incident case-control study in Sweden. Int. J. Cancer 1999; 83: 585-90.

26 IARC. IARC Monographs on the Evaluation of the Carcinogenic Risk of Chemicals to Humans, Vol. 44, Alcohol Drinking. Lyon: Lyon: International Agency for Research on Cancer, Lyon, 1988.

27 Joossens JV, Hill MJ, Elliott P, Stamler R, Stamler J, Lesaffre E et al. Stomach cancer, salt and nitrate in 24 countries. Proceedings of the Fifteenth International Congress on Nutrition, Adelaide, 27 Sept.-2 Oct. 1993, p. 381.

28 Correa P. Human gastric carcinogenesis: a multistep and multifactorial process. Cancer Res. 1992; 52: 6735-40.

29 Kato I, Dnistrian AM, Schwartz M, Toniolo P, Koenig K, Shore RE, Akhmedkhanov A, Zeleniuch-Jacquotte A, Riboli E. Serum folate, homocysteine and colorectal cancer risk in women: a nested case-control study. Br. J. Cancer 1999; 79: $1917-21$.

30 Ueland PM, Refsum H, Beresford SA, Vollset SE. The controversy over homocysteine and cardiovascular risk. Am. J. Clin. Nutr. 2000; 72: 324-32.

31 Baron JA, Beach M, Mandel JS, van Stolk RU, Haile RW, Sandler RS, Rothstein R, Summers RW, Snover DC, Beck GJ, Bond JH, Greenberg ER. Calcium supplements for the prevention of colorectal adenomas. Calcium Prevention Study Group. N. Engl. J. Med. 1999; 340: 101-7.

32 Bonithon-Kopp C, Kronborg O, Giacosa A, Rath U, Faivre J. Calcium and fibre supplementation in prevention of colorectal adenoma recurrence: a randomised intervention trial. European Cancer Prevention Organisation Study Group. Lancet 2000; 356(9238): 1300-6.

33 The Alpha-Tocopherol, Beta Carotene Cancer Prevention Study Group (ATBC). The effect of vitamin E and beta carotene on the incidence of lung cancer and other cancers in male smokers. N. Engl. J. Med. 1994; 330: 1029-35.

34 Omenn GS, Goodman GE, Thornquist MD, Balmes J, Cullen MR, Glass A, Keogh JP, Meyskens FL, Valanis B, Williams JH, Barnhart S, Hammar S. Effects of a combination of beta carotene and vitamin A on lung cancer and cardiovascular disease. N. Engl. J. Med. 1996; 334: 1150-5.

35 Blot WJ, Li JY, Taylor PR, Guo W, Dawsey S, Wang GQ, Yang GS, Zheng SF, Gail M, Li GY, Yu Y, Liu BQ, Tangrea J, Sun YH, Liu F, Fraumeni JF, Zhang YH, Li B. Nutrition intervention trials in Linxian, China: Supplementation with specific vitamin/mineral combinations, cancer incidence, and disease-specific mortality in the general population. $J$. Natl. Cancer Inst. 1993; 85: 1483-92.

36 Clark LC, Dalkin B, Krongrad A, Combs GFJr, Turnbull BW, Slate EH, Witherington R, Herlong JH, Janosko E, Carpenter D, Borosso C, Falk S, Rounder J. Decreased incidence of prostate cancer with selenium supplementation: Results of a double-blind cancer prevention trial. Br. J. Urol. 1998; 81: $730-4$.

37 Stewart BW, McGregor D, Kleihues P, eds. Principles of Chemoprevention. IARC Scientific Publication No. 139. Lyon: International Agency for Research on Cancer, 1996. 
38 Riboli E, Kaaks R. The challenge of multi-center cohort studies in the search for diet and cancer links. Am.J. Epidemiol. 2000; 151: 371-4.

39 Potischman N, Gail MH, Troisi R, Wacholder S, Hoover RN. Measurement error does not explain the persistence of a body mass index association with endometrial cancer after adjustment for endogenous hormones. Epidemiology 1999; 10: $76-9$.

40 Huang Z, Hankinson SE, Colditz GA, Stampfer MJ, Hunter DJ, Manson JE, Hennekens CH, Rosner B, Speizer FE, Willett WC. Dual effects of weight and weight gain on breast cancer risk. J. Am. Med. Assoc. 1997; 278: 1407-11. 